\title{
A Psicologia do Desenvolvimento na Educação Infantil
}

\author{
Eliana Chiavone Delchiaro ${ }^{1}$ \\ Jusmari Gumiero ${ }^{2}$ \\ Jessica Monique Silva ${ }^{3}$ \\ Soon Duk Kim Park ${ }^{4}$ \\ Elizângela Soares ${ }^{5}$ \\ Maria das Graças Martins do Nascimento Santos ${ }^{6}$
}

\begin{abstract}
Resumo
O presente artigo tem por objetivo analisar as contribuiçôes da Psicologia do Desenvolvimento para a Educação Infantil. Por meio dos estudos de Vigotsky, König e Mukhina procurou-se analisar os principais aspectos do desenvolvimento da criança de 0 a 3 anos que contribuíssem para a sugestão de atividades significativas para esta faixa-etária. Além desses autores foi feita uma análise da Base Nacional Comum Curricular (BNCC) onde foi possível encontrar diversas atividades relacionadas as etapas do desenvolvimento da criança e que abrangiam os cinco campos de experiências propostos pela BNCC. Logo, observou-se o quanto a Psicologia do Desenvolvimento tem para contribuir com a educação. Como os três primeiros anos da criança são cruciais para o seu desenvolvimento futuro. E de que maneira o professor pode utilizar esse conhecimento na elaboração de suas aulas para que estas sejam mais ricas em vivências significativas e que o processo de ensino-aprendizagem seja realmente significativo para o aluno.
\end{abstract}

Palavras Chave: Psicologia do Desenvolvimento. Vigotsky. Educação Infantil.

\begin{abstract}
This article aims analyses the contributions of Developmental Psychology to Early Childhood Education. Through the studies of Vigotsky, König and Mukhina, it was analyzed the main aspects of the development of children from 0 to 3 years old that contributed to the suggestion of significant activities for this age. In addition to these authors, an analysis of the National Curricular Common Base (BNCC) was carried out, where it was possible to find several activities related to the stages of child development that covered the five fields of experiences proposed by BNCC. Therefore, it was observed how much Development Psychology has to contribute to education. How the first three years of the child are crucial to its future development. And in what way teacher can use this knowledge in the elaboration of his classes so that they are richer in significant experiences and that the learning process be really meaningful for the student.
\end{abstract}

Keywords: Developmental Psychology. Vigotsky. Early Childhood Education.

\footnotetext{
${ }^{1}$ Mestre em Educação pela Pontifícia Universidade Católica de São Paulo, Graduada em Pedagogia, atualmente é diretora de escola no Centro Anhanguera de Promoção e Educação Social, professora assistente da Universidade Paulista e colaboradora da Prefeitura Municipal de São Paulo.

2 Mestre em Educação, Administração e Comunicação na área de concentração: Cultura, Memória e Tempo Presente pela Universidade São Marcos, Graduada em Pedagogia e pós graduada na área de Educação - concentração: Psicopedagogia. Atualmente é Coordenadora do Curso de Pedagogia e professora Adjunta na Universidade Paulista, Supervisora Técnico-Educacional no Serviço Social da Industria SESI/SP. E-mail: jusmari.gumiero@ docente.unip.br

3 Graduada em Administração e em Pedagogia. E-mail: jessicamonique_sales@hotmail.com

${ }^{4}$ Graduada em Pedagogia. E-mail: angelalondonpark@gmail.com

5 Graduada em Pedagogia. E-mail: elli2323@icloud.com

${ }^{6}$ Graduada em Pedagogia. E-mail: graca914@gmail.com
} 


\section{Introdução}

A Educação Infantil é o inicio e o fundamento do processo educacional. A entrada na creche ou na pré-escola significa, na maioria das vezes, a primeira separação das crianças dos seus vínculos afetivos familiares para incorporarem em uma situação de socialização estruturada.

A escolha desse tema se deu a partir da trajetória intelectual durante o curso de Pedagogia. Foi observado nas matérias relacionadas ao desenvolvimento da criança, o quanto é fundamental para formação docente saber sobre esse processo, pois o professor precisa entender a origem da criança, seu contexto social, seus estímulos e processo de desenvolvimento para trazer a ela uma metodologia de ensino que realmente faça a diferença em sua formação.

O interesse pelo estudo da Educação Infantil se deu após os estágios. Percebeu-se a falta de estímulos a essas crianças e a falta de importância dada ao tema do desenvolvimento. Com essa pesquisa espera-se articular uma reflexão teórica, com os problemas enfrentados na prática de muitas escolas.

O objetivo geral é compreender as características do desenvolvimento da criança da educação infantil e identificar atividades que sejam adequadas a crianças de 0 a 3 anos. Para isso objetiva-se estudar aspectos do desenvolvimento infantil a partir da perspectiva de Vigotsky. Examinar as principais etapas do desenvolvimento dos primeiros anos de vida da criança. Analisar a Base Nacional Comum Curricular e vincular essas informaçóes para identificar atividades adequadas a cada etapa do desenvolvimento da criança.

A metodologia utilizada foi uma pesquisa bibliográfica e qualitativa, por meio da análise de livros, sites, artigos e periódicos relacionados a área da educação e da psicologia. Dentre os autores estudados o foco principal foi dado a Lev Vigotsky, Valeria Mukhina e Karl König. Além do estudo das Diretrizes Curriculares Nacionais e da Base Nacional Comum Curricular para a Educação Infantil.

De acordo com Gil (2014), dentre os diversos métodos de abordagem, o que mais se encaixa neste trabalho é o método dialético. Um método de diálogo cujo foco é a contraposição e contradição de ideias que levam a outras ideias e que tem sido um tema central na filosofia ocidental e oriental. A tradução literal de dialética significa "caminho entre as ideias".

Portanto, com todo o acervo bibliográfico selecionado foi feita uma leitura crítica e avaliativa de todas as obras selecionadas, apresentando um diálogo entre os autores para encontrar informaçóes condizentes com o problema de pesquisa. A organização do trabalho se dará em três seçóes:

- Seção I - O Desenvolvimento Infantil a partir da perspectiva de Vigotsky.

- Seção II - Os três primeiros anos da criança

- Seção III - Atividades práticas na educação infantil, de 0 a 3 anos.

Este trabalho pretende contribuir com o aprendizado das crianças proporcionando atividades e projetos, para uma melhor atuação sociointerativa que traga diversidade para a sala de aula, novas ideias, novas propostas, estimulando a autonomia da criança e a construção do saber. Tudo isso baseado na psicologia do desenvolvimento. 


\section{Desenvolvimento Infantil a partir da perspectiva de Vigotsky}

Dentre os principais autores da Psicologia do Desenvolvimento, vale destacar Vigotsky por sua preocupação com a interação social e seus estudos voltados à infância.

A Teoria Sociocultural de Vigotsky afirma que formas complexas de pensamento tem suas origens nas interações sociais. Segundo ele, a aprendizagem de novas habilidades cognitivas por parte da criança é orientada por um adulto (ou por uma criança mais hábil, como um irmão mais velho) que estrutura a experiência de aprendizagem, processo chamado de andaime. Para criar um "andaime" adequado o adulto deve ganhar e manter a atençấo da criança, dar exemplo da melhor estratégia e adaptar todo o processo a Zona de Desenvolvimento Proximal da criança. (BOYDE; BEE, 2011 p. 63)

Esses estudos de Vigotsky sobre a Zona de Desenvolvimento proximal são um dos pontos mais interessantes em sua teoria uma vez que não pré define um determinado objeto de conhecimento. Cada criança pode estar em uma etapa diferente, mesmo sendo da mesma idade, o que o professor precisa saber é como utilizar isso para que a turma tenha um melhor desenvolvimento.

Faz-se necessário entender alguns conceitos utilizados por Vigotsky para compreender melhor sua teoria sobre o desenvolvimento da criança, tais como:

- Dialética e Mediação

- Instrumentos e Signos

- Pensamento e Linguagem

- Percepção e Imaginação

- Afetividade

O pensamento marxista foi para Vigotsky uma fonte científica valiosa para basear seus conceitos de dialética e mediação. Pode-se identificar os pressupostos filosóficos, epistemológicos e metodológicos de sua obra na teoria dialético-materialista.

O homem em seu diálogo com a natureza consegue testar suas hipóteses, planejar mentalmente, e corrigir possíveis problemas que possam surgir no processo da construção de algo. A ideia de que os processos mentais dependem das formas ativas de vida num ambiente apropriado tornou-se um princípio básico da psicologia materialista. Essa psicologia também admite que as açôes humanas mudam o ambiente de modo que a vida mental humana é um produto das atividades continuamente renovadas que se manifestam na prática social. (Karl Marx, O Capital in VIGOTSKY, 2007. p. 4)

Vigotsky enfatiza o processo histórico-social. Para ele, o sujeito é interativo, pois adquire conhecimentos a partir de relaçóes intra e interpessoais e de troca com o meio, a partir de um processo denominado mediaçáo.

Vigotsky distinguiu dois tipos de elementos mediadores: os instrumentos e os signos. Embora exista uma relação entre esses dois tipos de mediadores, eles têm características bastante diferentes.

A caracterização do uso de signos e de instrumentos como atividade mediada, orienta o comportamento humano na internalização dessas funções. Enquanto o signo constitui uma atividade in- 
terna dirigida para o controle do próprio sujeito, o instrumento é orientado externamente, para o controle da natureza. A apropriação de instrumentos e signos são apoios para que a criança realize determinadas atividades sozinha. (RIPPER, 1993).

O pensamento infantil é marcado pela ação da criança e pela exploração dos objetos concretos que manipula e investiga. $\mathrm{O}$ uso de instrumentos é uma evidência disso, uma vez que servem como mediadores, quando estabelecem relaçôes para realizar determinados fins, como subir em um banquinho para alcançar a prateleira em que está o biscoito, ou utilizar-se de uma vara para alcançar um objeto.

A apropriação de formas culturais de comportamento implica a reconstrução interna da atividade social, e a base que possibilita isso são as operações com signos. Dizer que as funções psíquicas do homem são de caráter mediatizado significa admitir a presença de elementos (signos) capazes de estabelecer ligaçóes entre a realidade objetiva, externa, e o pensamento (PALANGANA, 2015. p.103)

A memória mediada por signo é mais poderosa que a memória não mediada. Por exemplo, quando uma criança olha para o símbolo do Mc Donald's e lembra de um dia feliz que passou lá, fica mais fácil dela interiorizar e acessar essa informação mediante ao signo que ela já conhece.

Os signos ainda supóem as representaçôes mentais que podem substituir os objetos do mundo real. A função simbólica implica uma capacidade de abstração do concreto, possibilitando a representação de objetos em sua ausência. Quando uma criança brinca com um cabo de vassoura como se fosse um cavalo ela está simbolizando um objeto real por meio de signos.

O autor utiliza-se do exemplo do gesto que inicialmente o bebê faz para alcançar um objeto. Ao se movimentar em direção do objeto, seus dedos acabam fazendo movimentos que são interpretados pelo adulto como o gesto de apontar e não de pegar. Na interação com o adulto e por meio de sua interpretação, o significado transforma-se do ato de pegar, para o de apontar.

Outro processo pelo qual a criança passa em seus primeiros anos de vida é a aquisição da linguagem e esta se relaciona com o pensamento. A partir do nascimento, as crianças vivem num mundo de produtos históricos do trabalho social. Elas aprendem a comunicar-se com os outros a sua volta e desenvolvem relaçôes com objetos por meio da ajuda de adultos. As crianças assimilam a linguagem e usam-na para analisar, generalizar e codificar suas experiências. Elas nomeiam objetos, usando expressôes estabelecidas anteriormente na historia, encaixando esses objetos em categorias e adquirindo conhecimentos.

A linguagem age decisivamente na estrutura do pensamento e é ferramenta básica para a construção de conhecimentos (STADLER et al., 2004). Interfere no desenvolvimento intelectual da criança desde seu nascimento. Porém, a linguagem e o pensamento aparecem no momento em que a criança já apresenta função simbólica. Passa a expressar-se por meio das palavras, aprendendo a nomear os objetos, interessada e curiosa por saber o nome das coisas, voltada para o mundo externo, para a exploração dos objetos e da própria fala, evolui rapidamente e amplia seu vocabulário. Essa fase Vigotsky denominou fase intelectual da fala, diferentemente da fase anterior, pré-intelectual, em que o pensamento e a linguagem ainda não estão conectados. 
Nesse momento a fala já expressa um significado e um sentido comum. No início, a palavra apresenta um caráter generalizante, e aos poucos vai se transformando e delimitando sua especificidade. Por exemplo, a criança pequena aprende a falar "au-au", e no início "au-au" serve para designar não só os cachorros mas também outros animais. Esse momento da fala nos remete à fundamental importância da estreita ligação entre o desenvolvimento da fala e o do pensamento, uma vez que os significados das palavras são determinados por ambos (BASTOS, 2014. p.58)

Os educadores não devem cerceá-las. Devem ouvi-las e agir como mediadores, auxiliando também em sua construção intelectual dando voz as crianças, o que é fundamental.

A função inicial da linguagem é evidenciada por meio das diferentes expressóes emocionais, que apresentam uma função predominantemente social. Em seguida aparece a fala egocêntrica, aquela que acompanha as açóes da criança expressa em voz alta, tendo uma clara função de auxiliar seu planejamento, sua ação sobre os objetos. Por exemplo, a criança que vai subir em um banquinho para pegar a bolacha e diz "Gabriela vai subir para pegar bolacha". A fala egocêntrica, está intimamente relacionada com a inteligência prática, com a resolução de problemas ou situações e com a mediação de instrumentos. Diferentemente de Piaget, Vigotsky concebe que a linguagem é primeiramente influenciada pelo contexto externo, sócio-histórico, passando num momento posterior a ter uma função intra-psicológica.

As articulaçóes propostas por Vigotsky a partir da significativa conexão entre o pensamento e a linguagem podem evidenciar uma verdadeira transformação ao longo do desenvolvimento, marcado pela transição da dimensão biológica para a sócio-histórica. "A linguagem fornece os conceitos e as formas de organização do real que constituem a mediaçáo entre o sujeito e o objeto de conhecimento" (FOSSILE, 2010).

Vigotsky afirma que a linguagem possui duas funções básicas: intercâmbio social e pensamento generalizante. A função de intercâmbio social é bem visível nos bebês, uma vez que conseguem, por meio de gestos, expressōes e sons, demonstrar seus sentimentos, desejos e necessidades. A função de pensamento generalizante pode ser exemplificada quando falamos, por exemplo, a palavra boi. Independentemente de ter visto de perto algum boi ou de comer ou não sua carne, nosso pensamento classifica tal palavra na categoria animais e nos remete à sua imagem.

Não há uma separação radical entre «linguagem»e «mundo» já que a «realidade» é constituída exataa mente pelo modo como aprendemos a linguagem e a usamos. Sendo assim o contexto em que a criança está inserida é de vital importância para seu desenvolvimento.

A percepção é uma característica também desenvolvida pela criança nos primeiros anos. Dentro do diálogo sócio-histórico a percepção depende de práticas humanas historicamente estabelecidas que podem não só alterar os sistemas de codificação usados no processamento da informação, mas também influenciar a decisão de situar os objetos percebidos, que podem mudar o desenvolvimento histórico.

A psicologia moderna distingue certos níveis dentro da imaginação, afirmando que a imaginação "reprodutiva" difere da imaginação criativa. A imaginação pode estar firmemente ligada à experiência prática ou pode ocorrer em um sistema de pensamento lógico-verbal (LURIA, 2013. p. 181). 


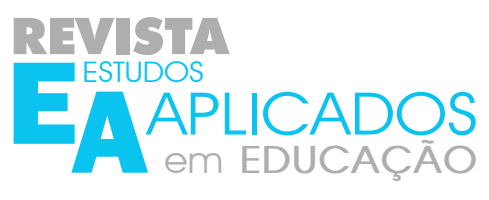

A psicologia da criança muda de uma descrição indiferenciada de fatos a respeito da imaginação para uma análise articulada. Os psicólogos começaram supondo que crianças têm uma vida de fantasia vigorosa, ilimitada e terminaram por estabelecer que a imaginaçáo das crianças jovens é confinada aos limites da memória imediata. Ela tem apenas uma natureza "reprodutiva", e a verdadeira imaginação criativa vai aparecer pela primeira vez num estágio de desenvolvimento posterior (LURIA, 2013. p. 181).

Nota-se que a imaginação é pré-requisito essencial para processos de desenvolvimento futuros, como a alfabetização e lógica matemática. Além de demonstrar de maneira convincente que a estrutura da atividade cognitiva não permanece estática e as formas de processos cognitivos variam quando as condiçóes da vida social mudam e quando rudimentos de conhecimento são adquiridos.

Essa análise do ambiente desde a Educação Infantil permite avaliar o quanto fatores externos interferem no processo de desenvolvimento cognitivo da criança. Se a criança é criada num ambiente sem estímulos onde ela é considerada atrasada, ou de menor valor, ela não terá o incentivo necessário para se desenvolver de forma completa. Estará sempre a quem do seu possível desenvolvimento.

Vigotsky fazia várias críticas às concepçôes inatista e ambientalista do desenvolvimento humano. A inatista diz que a criança nasce já pronta e só espera o amadurecimento se manifestar, e a ambientalista vê o indivíduo como uma folha em branco que só reage frente a pressões do meio. No entanto, Vigotsky vê o indivíduo como um ser ativo capaz de modificar a si próprio e o meio em que vive (REGO, 2014)

Algumas abordagens sobre a educação feitas por Vigotsky, envolvendo o papel da escola e a importância do conhecimento sistematizado. Na sua abordagem a criança primeiro aprende para depois se desenvolver, constrói seu desenvolvimento sendo um sujeito ativo em sua construção, apresenta a importância da imitação nas brincadeiras para o desenvolvimento de valores e como o professor deve agir perante tudo isso.

É necessário ressaltar que na abordagem Vigotskiana, o que ocorre não é uma somatória entre fatores inatos e adquiridos e sim uma interação dialética que se dá, desde o nascimento, entre o ser humano e o meio social e cultural que se insere.

Quando se trata da abordagem Vygotskiana para a educação não se encontra receita de sucesso no plano pedagógico, mas sim, contribuiçōes em suas reflexões. O diálogo entre teoria e prática pedagógica, traz reflexões e compreensôes sobre como aplicar a teoria na prática e como a reflexão sobre a prática pode criar novas teorias, resultando assim num ensino-aprendizagem e desenvolvimento constante.

Rego (2014) fala dos estudos que Vigotsky fez sobre a afetividade, pois para ele o afeto e a razão deveriam andar juntos, estudando o homem como um todo. Segundo ela, Vigotsky concebe o homem como um ser que raciocina, pensa, mas que também se emociona, deseja, imagina e se sensibiliza. E em sua perspectiva, cognição e afeto não estão dissociados no ser humano.

A autora comenta um texto original de Vigotsky, onde ele afirma que a aprendizagem é um momento intrinsecamente necessário para que se desenvolvam na criança as características humanas que não são naturais, mas sim formadas historicamente. Fala sobre o nível de desenvolvimento efetivo e a área de desenvolvimento potencial. Explica que uma boa aprendizagem não trabalha a área onde a criança já efetuou seu desenvolvimento e sim está sempre à frente ao desenvolvimento.

Por isso, reflexóes sobre a problemática envolvida na complexa relação das teorias psicológicas e a dimensão da prática educativa são necessárias. Essa reflexão é particularmente oportuna visto que as ideias de 
Vigotsky vêm alcançando no Brasil uma significativa repercussão. Por existir várias outras dimensóes a serem trabalhadas na escola, como política, ética e histórica, não se deve apegar a uma só teoria, já que o próprio Vigotsky foi um pesquisador inquieto e interdisciplinar.

\section{Os três primeiros anos da criança}

Nesta seção abordam-se os aspectos marcantes do desenvolvimento da criança de 0 a 3 anos, segundo os autores Karl Konig e Valeria Mukhina. Dentre os vários aspectos do desenvolvimento da criança nesse período serão destacados três pontos principais:

- A aquisição do andar ereto,

- O aprendizado da língua materna

- O despertar do pensar.

König (2011) caracteriza o movimento motor como algo integral. Dentro do útero o ser humano já possui suas capacidades motoras, mas é a partir do nascimento que passa dominá-las de forma ordenada. Os seres humanos realizam diversos processos motores. Porém de todos os processos o mais característico do ser humano é o andar ereto, isto o coloca em constante luta contra a gravidade.

Segundo Mukhina (1995), quando a criança consegue caminhar, sendo seu meio principal de alcançar os objetos, desde os primeiros meses até completar um ano, passa por obstáculos com dificuldades ( descer ,subir, agachar-se, passar entre os obstáculos, etc.). Ela passa a adaptar-se ao equilíbrio, a dominar o próprio corpo, ampliar sua percepção visual e a ir em busca de objetos que não estão ao seu alcance. Andar para a criança é algo que a satisfaz e dominar esta capacidade, se tornará algo automático.

Ambos os autores consideram o andar ereto como o primeiro passo a ser dominado pela criança no primeiro ano de vida. Mas para chegar a esse ponto ela passa por um longo processo de controle dos próprios movimentos, do conhecimento do próprio corpo e suas capacidades.

Em geral, no primeiro trimestre de vida o bebê estabiliza sua cabeça, no segundo suas costas e mãos, quando ele começa a ficar "apalpador", e no terceiro trimestre começa o exercício das pernas, para no fim do primeiro ano poder andar ereto (KONIG, 2011).

O aprender a caminhar na visão de König (2011), além do domínio motor, é também uma manifestaçáo da consciência do ser humano como algo distinto do mundo em seu redor, uma separaçáo. O domínio motor que se passa no primeiro ano do bebê quando visto como um processo holístico revela também um desenvolvimento da consciência em relação a diferença do corpo e do que está fora dele, a liberdade de andar e agarrar é o mesmo que uma autoafirmação.

Entre os movimentos do bebê alguns são inatos e outros são adquiridos pela aprendizagem (MUKHINA, 1995, p.41). Já König (2011, p. 20) salienta que esses movimentos inatos devem desaparecer para dar lugar aos movimentos adquiridos por aprendizado, em caso de crianças que por ventura náo tem um desenvolvimento psicomotor saudável os movimentos inatos se mantém e tornam-se mais exagerados, e não se efetiva o aprendizado do andar. 
Veja no quadro a seguir as principais etapas do desenvolvimento da criança até alcançar o andar ereto segundo os autores König (2011) e Mukhina (1995):

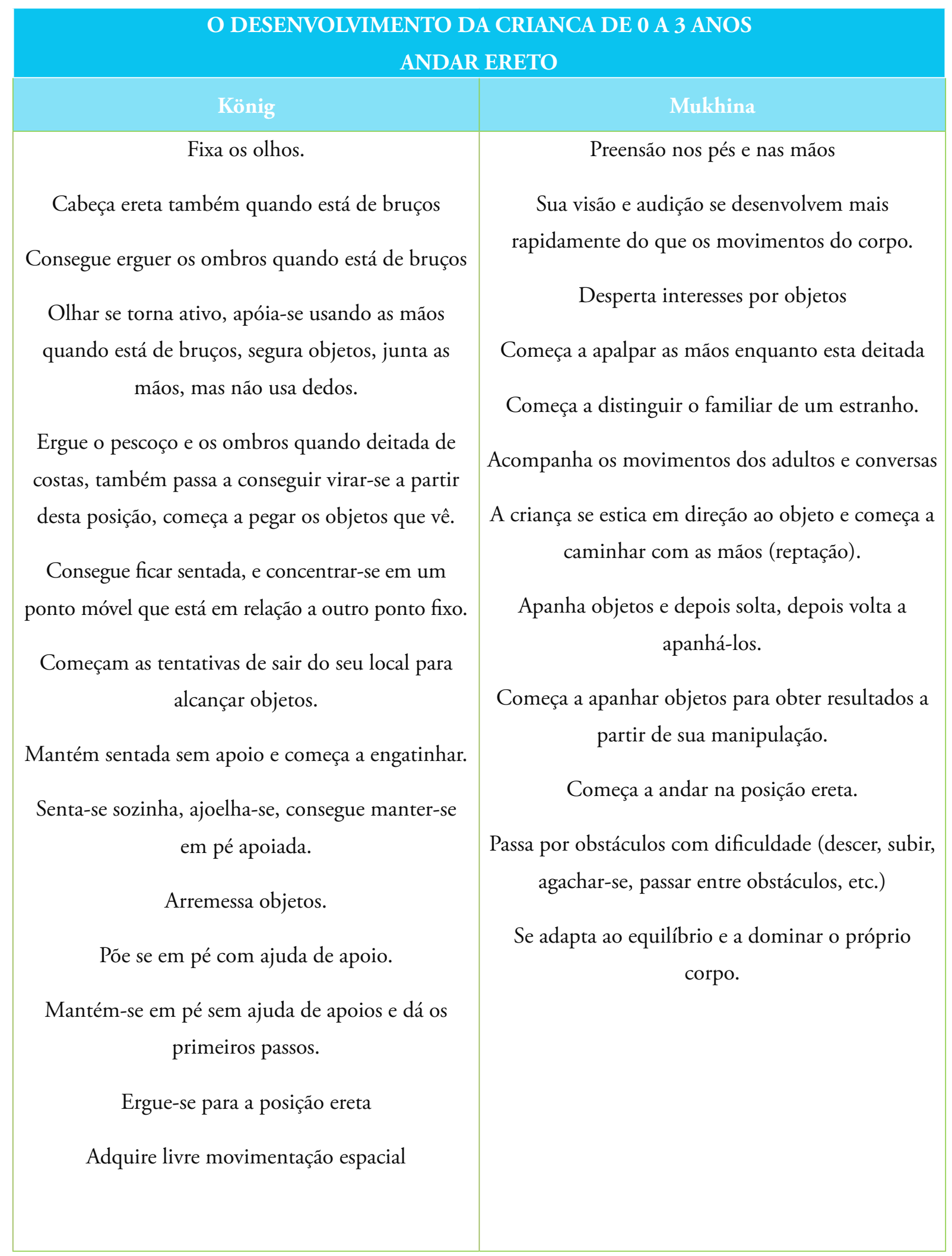

Fonte: Elaborado pelas autoras 
Não há um dia exato para criança desenvolver cada uma dessas atividades, nem uma ordem fixa que não possa ser mudada. Este quadro apresenta uma sequência que geralmente é seguida pela maioria das crianças. Ambos os autores falam da relação do bebê com o objeto e como isso o estimula a andar para alcançar esses objetos. Da sua relação com a gravidade e da percepção do próprio corpo e do que acontece a sua volta.

Após a aquisição do andar ereto, a próxima conquista significativa feita pela criança é o aprendizado da língua materna. A linguagem é um fator fundamental para que o desenvolvimento infantil ocorra de forma harmônica em todas as esferas, seja do ponto de vista social, relacional ou ao nos referirmos à aprendizagem formal. (MOUSINHO, 2008).

A primeira infância é o período primordial para o desenvolvimento da linguagem infantil, é quando a criança faz novas relaçóes com o meio circundante. Por meio das relaçóes sociais a criança começa a compreender a linguagem (MUKHINA, 1995).

Segundo König (2011) o bebê quando nasce é um cosmopolita, seu balbuciar o habilita para aprendizagem de qualquer língua, é o que o torna apto ao aprendizado da língua materna de forma tão natural e ágil, é a própria linguagem que se desenvolve dentro dele e não uma espécie de mecanismo natural que o torna apto a reconhecer e aprender línguas.

A linguagem esta diretamente ligada ao corpo da criança. Conforme a criança vai crescendo e se desenvolvendo ela passa também a domina-la. A partir daí ela começa a se expressar e externar seus desejos e suas vontades de forma mais clara. Suas relações sociais vão tendo mais qualidade e esse período se torna crucial para seu desenvolvimento futuro.

König (2011) e Mukhina (1995) falam das etapas pelas quais a criança passa nesse processo de aquisição da linguagem, conforme vemos na tabela a seguir:

\begin{tabular}{|c|c|}
\hline \multicolumn{2}{|c|}{$\begin{array}{l}\text { O DESENVOLVIMENTO DA CRIANCA DE } 0 \text { A } 3 \text { ANOS } \\
\text { O APRENDIZADO DA LÍNGUA MATERNA }\end{array}$} \\
\hline König & Mukhina \\
\hline Grito & Emissão de sons \\
\hline Balbuciar & Imitação do ritmo dos sons \\
\hline O ouvir dos nomes & Balbuciar. \\
\hline Imitação & Pronuncia silabas tentando imitar o adulto. \\
\hline $\begin{array}{l}\text { Relacionar palavras e objetos, palavras e pessoas, } \\
\text { palavras e situaçóes. }\end{array}$ & $\begin{array}{l}\text { Aperfeiçoa o movimento dos lábios, da língua e } \\
\text { da respiração. }\end{array}$ \\
\hline Sentenças uni-vocabular. 40 a 70 palavras. & A criança estabelece relação entre a palavra dita \\
\hline Período do dizer. & e o objeto definido pela palavra. \\
\hline $\begin{array}{l}\text { A criança começa a captar de forma súbita e espontânea } \\
\text { que cada coisa tem seu nome. São adquiridas de } 400 \text { a }\end{array}$ & $\begin{array}{l}\text { A criança estabelece relação entre o objeto e seu } \\
\text { nome. }\end{array}$ \\
\hline $\begin{array}{l}500 \text { palavras. } \\
\text { Período do denominar }\end{array}$ & $\begin{array}{l}\text { A criança consegue pronunciar de } 4 \text { a } 15 \\
\text { palavras. }\end{array}$ \\
\hline $\begin{array}{l}\text { Adquire as bases para uma primeira formação primitiva } \\
\text { de frase }\end{array}$ & $\begin{array}{l}\text { Quando a criança começa a compreender a } \\
\text { linguagem do adulto procura ampliar essa } \\
\text { relação para conhecer novos nomes de objetos. }\end{array}$ \\
\hline $\begin{array}{l}\mathrm{Na} \text { criança surge o impulso de relatar, e este impulso } \\
\text { acorda a linguagem; agora chega-se ao que denomina-se } \\
\text { conversar. }\end{array}$ & $\begin{array}{l}\text { A criança passa a conhecer de } 30 \text { a } 100 \\
\text { palavras. }\end{array}$ \\
\hline $\begin{array}{l}\text { Começa o período do argumentar } \\
\text { Aquisição da linguagem materna. Reagir com sensatez a }\end{array}$ & $\begin{array}{l}\text { O adulto começa a exigir que a criança fale } \\
\text { claramente e formule seu pedido com as } \\
\text { palavras corretas. }\end{array}$ \\
\hline palavra que lhe é dirigida. & $\begin{array}{l}\text { A criança assimila o sistema gramatical da } \\
\text { língua materna. } \\
\text { A criança utiliza até } 1500 \text { palavras. }\end{array}$ \\
\hline
\end{tabular}




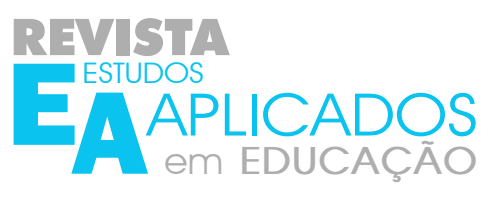

Os autores se completam em muitos pontos. Primeiro, ambos falam da emissão de sons ou gritos como sendo a primeira etapa para a aquisição da linguagem materna. Segundo König (2011), o balbuciar também é levantado como ponto importante nesse processo. A relação entre o adulto e a criança é fator determinante para ambos os autores para que a aquisição da linguagem seja concretizada.

Segundo Mukhina (1995), os melhores meios para o desenvolvimento da linguagem neste período são: as contações de histórias utilizando livros, fantoches, músicas com gestos, repetição de palavras e açôes. É preciso propiciar momentos, nos quais a criança necessite verbalizar o que quer e o que está sentindo, tanto com os próprios colegas como com o professor. Para isso é necessário ter paciência e não atender a primeira manha ou choro da criança. Isso acontece com frequência, na troca de brinquedos, uma criança toma o brinquedo de outra e tem início o choro. Neste momento, o professor deve intervir e incentivar o diálogo e a negociação. Há momentos em que as crianças querem que o professor atenda os pedidos feitos por gestos e gemidos. É necessário pedir para a criança verbalizar o que deseja. Deve haver um consenso, pois não é aconselhável irritar a criança e obrigá-la a falar, mas sim, ajudá-la e incentivá-la nos momentos em que aceita ajuda.

Com o tempo, a linguagem passa a ser o meio principal para as experiências sociais. Com a aquisição da linguagem, a criança desenvolve vários processos psíquicos, como a memória, o diálogo, etc. Esses processos formam a base para o avanço da criança para próxima etapa, o despertar do pensar.

O desenvolvimento da mente se dá por diferentes experiências vividas pela criança, principalmente as realizadas com objetos e instrumentos no meio social.

Se uma criança que perceber que um bastão pode ajudá-la a alcançar um brinquedo, ela brincará de alcançar o brinquedo repetidas vezes. Em uma outra ocasião, a criança repetirá a ação usando o bastáo para alcançar outros objetos que estáo fora do seu alcance, apenas por pensar e lembrar do que havia feito anteriormente. Ou seja, foi interiorizada uma ação que poderá ser usada para resolver vários tipos de problema semelhantes, sem a necessidade de testar novamente todas as propriedades do objeto.

König (2011) busca estabelecer uma diferenciação entre o aprendizado da língua e o pensar. Segundo ele muitos processos que atribuiríamos a qualidade de pensamento são meramente o desenvolvimento da linguagem na criança. É a linguagem bem desenvolvida, a memória e a fantasia que permitem o nascimento do pensamento e do "eu". Quando uma criança chama o leite desnatado de "leite de água", ela esta apenas inventando uma palavra nova, ou estabelecendo relaçóes a partir daquilo que ela vê. Mas quando ela é capaz de estabelecer relaçôes de causa e efeito(se... então...”), por exemplo: “se a mamãe saiu de casa hoje, então ela não virá para a janta.” é que ela passa realmente a fase pensante.

Outra base essencial para o desenvolvimento do pensamento é a memória. Segundo König (2011), a criança desenvolve a memória em três etapas, primeiro de forma localizada, depois de forma rítmica e por fim de forma lógica. A primeira forma de recordação surge no primeiro ano quando a criança pode associar locais à acontecimentos, como chorar quando está no trocador. A segunda forma está associado ao ritmo das palavras e dos sons e se desenvolve ao longo do segundo ano. Tendo conquistado a linguagem ela passa a manifestar a memória lógica. 
Ao longo do segundo ao terceiro aniversário, ocorre o desenvolvimento da fantasia e do brincar. Até então é claro que a criança brinca, mas a partir de agora ela adiciona fantasia nas brincadeiras. A fantasia e o brincar, para König, estão intimamente ligados, é impossível conceber brincadeira sem fantasia e fantasia sem brincadeira.

De acordo com Mukhina (1995), o interesse pela brincadeira do amigo ajudará a criança a estabelecer contato com o outro paulatinamente, despertando o interesse de brincar com quem estiver próximo e aos poucos entender as regras de convivência. A brincadeira ou a atividade lúdica faz parte do desenvolvimento psíquico da criança. Durante o brincar a criança desenvolve a percepção visual, a coordenação motora, a atenção, a linguagem, a memória e a imaginação.

Algumas atividades podem auxiliar nas aprendizagens e desenvolvimento infantis, como brincadeiras de movimento ao ar livre, artes utilizando variadas técnicas, contação de histórias, dança e música, mudança de decoração da sala onde fica a criança. Um ambiente amplo e arejado ajudarão na prática pedagógica. A escola é um ambiente que possibilita à criança vivenciar novas relaçôes com o adulto e com outras crianças, além de proporcionar atividades socialmente necessárias para o desenvolvimento integral da criança.

König (2011) descreve outro evento que ocorre na vida das crianças, nesta fase entre os 2 e 3 anos de idade, é o nascimento do "eu". Assim que a linguagem e fantasia, junto com o brincar, estão desenvolvidos o suficiente, a criança passa a perceber-se como sendo um "eu" e não só mais um nome entre os outros.

Estes conhecimentos culminam num outro ponto característico desta fase da vida da criança, a teimosia. Desde que aprendeu a andar, e se diferenciou materialmente do mundo circundante, até que adquiriu a fala e se apoderou de muitos objetos e coisas, a criança não era propriamente um "eu" aceitava mais ou menos de bom grado tudo que lhe era imposto. Então no terceiro ano ela passa a relacionar tudo isso que conquistou à sua vontade, esta afirmação se manifesta grande parte das vezes como pura teimosia. Os pais precisam nesse momento dar o exemplo do perdão incondicional, da paciência e da compreensão.

No quadro abaixo vamos ver um pouco desse processo de desenvolvimento da criança até o despertar do pensar e o reconhecimento do "EU". É possível notar que os outros processos descritos anteriormente, o andar ereto e a aquisição da linguagem materna, são pré-requisitos para que a criança chegue a esse próximo passo. Isso mostra como o desenvolvimento da criança é um processo contínuo e interligado. A criança desde os 0 anos de idade precisa se desenvolver como um todo, em seus aspectos físico, motor, afetivo, cognitivo e social. Cada etapa do seu desenvolvimento é resultado de um progresso em todas essas áreas. 


\section{König}

$\mathrm{O}$ aperfeiçoamento da linguagem

Aquisição da memória

Brincar

Gradual aquisição de uma noção de tempo e espaço

Compreensão das percepçóes e suas metamorfoses.

Nascimento do "eu"

\section{Mukhina}

Estabelecimento de relaçóes e conexóes entre os objetos.

Formação do pensamento prático

Resolução de problemas mentalmente por meio de operaçóes mentais elementares, valendo-se de imagens.

Brincar

Formação do pensamento imaginativo.

Sinterizações práticas, que se fixam na palavra.

Assimilação da função semiótica da consciência

Auto-identificação

Fonte: Elaborado pelas autoras

As transformaçóes quantitativas que a criança experimenta nos três primeiros anos de vida são tão notáveis que certos psicólogos consideram que o desenvolvimento do homem pode ser dividido em duas metades: do nascimento até os 3 anos e dessa idade em diante (MUKHINA, 1995, p. 103). Portanto, o estudo da primeira infância é essencial ao professor, por ser o período em que a criança desenvolve toda a base para sua formação.

Cabe aos professores analisar as informaçôes oferecidas sobre o processo de desenvolvimento da criança para mediar aquilo que é relevante ou não para a aprendizagem. Dessa forma, será possível vincular a teoria à prática e entender que o educar vai além de atividades dirigidas e centralizadas na visão do adulto.

Logo, a práxis se torna imprescindível nesse processo, sendo algo contínuo e diário fazendo com que o professor busque a teoria, reflita e transforme o ambiente no qual está inserido.

\section{Atividades práticas na educação infantil, de 0 a 3 anos}

Diante de tudo que foi exposto até agora como é possível incluir os conhecimentos sobre o desenvolvimento infantil a vivência na sala de aula? Como o professor pode planejar atividades para crianças de 0 a 3 anos utilizando estes conhecimentos?

A Constituição Federal de 1988 assegura que o atendimento em creche e pré-escola, às crianças de 0 á 6 anos de idade, torna-se dever do estado. Posteriormente, com promulgação da LDB,em 
1996, a educação infantil passa a ser parte integrante da educação básica, situando no mesmo patamar que o ensino fundamental e o ensino médio. E é a partir da modificação introduzida na LDB em 2006 que antecipou o acesso ao ensino fundamental aos 6 anos de idade, que a educação infantil passa a atender a faixa etária de 0 a 5 anos (BRASIL, 2017).

Tanto as Diretrizes Curriculares Nacionais quanto a Base Nacional Comum Curricular definem a Educação Infantil como parte importante da Educação Básica e um direito de todos. Sendo dever do estado a oferta também nesta modalidade de ensino.

A Base Nacional Comum Curricular (BNCC) é um documento de caráter normativo que define o conjunto orgânico e progressivo de aprendizagens essenciais que todos os alunos devem desenvolver ao longo das etapas e modalidades da Educação Básica. Aplica-se à educação escolar, tal como a define o $\$ 1^{\circ}$ do Artigo $1^{\circ}$ da Lei de Diretrizes e Bases da Educaçáo Nacional (LDB, Lei no 9.394/1996), e indica conhecimentos e competências que se espera que todos os estudantes desenvolvam ao longo da escolaridade.

$\mathrm{Na}$ primeira etapa da Educação Básica, e de acordo com os eixos estruturantes da Educação Infantil (interaçôes e brincadeiras), devem ser assegurados seis direitos de aprendizagem e desenvolvimento (conviver, brincar, participar, explorar, expressar e conhecer-se), para que as crianças tenham condiçóes de aprender e se desenvolver. Considerando os direitos de aprendizagem e desenvolvimento, a BNCC estabelece cinco campos de experiências, nos quais as crianças podem aprender e se desenvolver:

- $\mathrm{O}$ eu, o outros e o nós.

- Corpo, gestos e movimentos;

- Traços, sons, cores e formas;

- Oralidade e escrita;

- Espaços, tempos, quantidades, relações e transformaçóes.

Entende-se a criança hoje como ser que observa, questiona, levanta hipóteses, conclui, faz julgamentos e assimila valores construindo conhecimentos sistematizados por meio da ação e nas interaçóes com o mundo físico e social. Por isso reitera-se a importância e a necessidade de haver intencionalidade educativa nas práticas pedagógicas na Educação Infantil, tanto na creche quanto na pré-escola. A intencionalidade do processo educativo pressupóe o monitoramento das práticas pedagógicas e o acompanhamento da aprendizagem e do desenvolvimento das crianças.

Segundo as Diretrizes Curriculares Nacionais para Educação Infantil (DCNEI) têm se mostrado prioritárias as discussões sobre como orientar o trabalho junto às crianças de até três anos em creches. Por isso o foco desse capitulo é sugerir atividades para serem trabalhadas com crianças desta faixa etária, baseando-se no processo de desenvolvimento da criança, segundo a Psicologia do Desenvolvimento, e os campos de experiência apresentados na BNCC. Serão abordados apenas quatro sugestôes por campo de experiência, embora existam mais sugestóes que podem ser encontradas. 
Campo de Experiência: $\mathrm{O}$ eu, o outro e o nós

0 a 1 ano

Objetivos

Atividades

Objetivos

1 a 3 anos

- Demonstrar afetividade;

- estabelecer vínculos com

Perceber que suas ações as

têm efeitos nas outras crianças e nos adultos.

pessoas que fazem parte do seu cotidiano;
Demonstrar atitudes de cuidado e solidariedade na interação com crianças e adultos.
- Revelar preferência de amizade gostos e afetividade em relação a algumas crianças e adultos,
Perceber as possibilidades e os limites de seu corpo nas brincadeiras e interações das quais
- Segurar os objetos, leválos à boca e atirá-los; - engatinhar, movimentarse e empurrar objetos

\section{Demonstrar imagem} positiva de si e confiança em sua capacidade para enfrentar dificuldades e desafios.
- reconhecer-se pelo próprio nome;

\section{Atividades}

\section{participa. \\ Interagir com crianças da mesma faixa etária e adultos ao explorar materiais, objetos, brinquedos.}

- Brincar com água, terra, areia, fazendo pasta, conhecendo texturas;
Compartilhar os objetos e os espaços com crianças da mesma faixa etária e adultos.
- brincar e interagir com as demais crianças;
- perceber situaçóes,

Comunicar-se com os colegas e os adultos, buscando compreendê-los e fazendo-se compreender. falar, sentir, pensar, perguntar, devendo o(a) professor(a) considerar todas essas suas formas de relacionar-se 


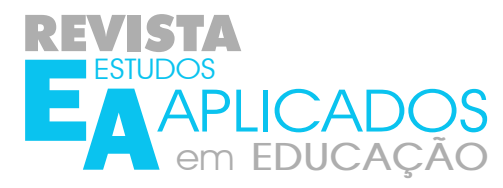

\begin{tabular}{|c|c|c|c|}
\hline \multicolumn{4}{|c|}{ Campo de Experiência: Corpo, gestos e movimento } \\
\hline \multicolumn{2}{|c|}{0 a 1 ano } & \multicolumn{2}{|c|}{1 a 3 anos } \\
\hline Objetivos & Atividades & Objetivos & Atividades \\
\hline $\begin{array}{l}\text { Movimentar as partes } \\
\text { do corpo para exprimir } \\
\text { corporalmente emoções, } \\
\text { necessidades e desejos. }\end{array}$ & $\begin{array}{l}\text {-Erguer a cabeça, rolar, } \\
\text { sentar, apoiar, rastejar, } \\
\text { engatinhar, etc.: desafios } \\
\text { corporais fora do berço; }\end{array}$ & $\begin{array}{l}\text { Apropriar-se de gestos e } \\
\text { movimentos de sua cultura } \\
\text { no cuidado de si e nos jogos } \\
\text { e brincadeiras. }\end{array}$ & $\begin{array}{l}\text { - Chutar e arremessar } \\
\text { bola de diferentes materiais } \\
\text { (bexiga, isopor, plástico, } \\
\text { borracha, pano, couro); }\end{array}$ \\
\hline $\begin{array}{l}\text { Ampliar suas possibilidades } \\
\text { de movimento em espaços } \\
\text { que possibilitem exploraçóes } \\
\text { diferenciadas. }\end{array}$ & $\begin{array}{l}\text {-Explorar o ambiente } \\
\text { (chão, tapete, cercado, } \\
\text { carrinho, berço, solarium, } \\
\text { grama, refeitório e outros) }\end{array}$ & $\begin{array}{c}\text { Explorar formas de } \\
\text { deslocamento no espaço } \\
\text { (pular, saltar, dançar), } \\
\text { combinando movimentos e } \\
\text { seguindo orientaçóes. }\end{array}$ & $\begin{array}{l}\text { - Deslocar-se pela sala; } \\
\text { - Caminhar em uma } \\
\text { superfície plana, } \\
\text { equilibrando - se; } \\
\text { - Subir escadas }\end{array}$ \\
\hline $\begin{array}{l}\text { Participar do cuidado do } \\
\text { seu corpo e da promoçáo do } \\
\text { seu bem-estar. }\end{array}$ & $\begin{array}{c}\text { — favorecer condiçóes } \\
\text { para que as crianças } \\
\text { estejam cuidadas, limpas e } \\
\text { saudáveis, estimulando a } \\
\text { responsabilidade } \\
\text { e autonomia com a higiene e } \\
\text { a saúde do próprio corpo; }\end{array}$ & $\begin{array}{l}\text { Demonstrar progressiva } \\
\text { independência no cuidado } \\
\text { do seu corpo. }\end{array}$ & $\begin{array}{l}\text { - ajudar os pequenos na } \\
\text { transição da mamadeira } \\
\text { para a colher e o copo, bem } \\
\text { como da colher para os } \\
\text { demais talheres; }\end{array}$ \\
\hline $\begin{array}{l}\text { Imitar gestos, sonoridades } \\
\text { e movimentos de outras } \\
\text { crianças, adultos e animais. }\end{array}$ & $\begin{array}{l}\text { - perceber variaçóes sonoras } \\
\text { (som } \\
\text { alto, baixo, grave e agudo); } \\
\text { _ ouvir música de ritmos e } \\
\text { culturas diferentes; }\end{array}$ & $\begin{array}{l}\text { Deslocar seu corpo no } \\
\text { espaço, orientando-se por } \\
\text { noçóes como em frente, } \\
\text { atrás, no alto, embaixo, } \\
\text { dentro, fora etc. }\end{array}$ & $\begin{array}{c}\text { - Oportunizar às crianças } \\
\text { espaços amplos, na } \\
\text { instituição, e nas suas } \\
\text { proximidades, o direito } \\
\text { de correr, pular, saltar e se } \\
\text { movimentar } \\
\text { livremente; }\end{array}$ \\
\hline
\end{tabular}

Fonte: Elaborado pelas autoras 


\section{Campo de Experiência: Traços, sons, cores e formas}

\section{0 a 1 ano}

\section{1 a 3 anos}

\section{Objetivos}

Atividades
Objetivos

- brincar com a produção

de sons com diferentes

materiais, ouvir músicas

e aprender a cantar;

com o próprio corpo e

com objetos do ambiente.

\begin{tabular}{|c|c} 
músicas, acompanhados de \\
movimentos \\
corporais;
\end{tabular}

Utilizar materiais variados com possibilidades de manipulação (argila, massa de modelar), criando objetos tridimensionais.

- manipular objetos de diferentes

formatos e tamanhos.

\section{Expressar-se por meio} de linguagens como a do desenho, da música, do movimento corporal, do teatro.

Utilizar diferentes fontes sonoras disponíveis no ambiente em brincadeiras cantadas, cançôes, músicas e melodias.
Atividades
Explorar diferentes fontes sonoras e materiais para acompanhar brincadeiras cantadas, canções, músicas e melodias.
- brincar com a produçáo de sons

com diferentes materiais, ouvir músicas e aprender a cantar;
Criar sons com materiais,

- garantir às crianças o direito de cantar e dançar, ouvir e contar histórias;
- incentivar a expressão das crianças por meio de dramatizaçôes, desenhos, pinturas, colagens e modelagem;

- utilizar objetos diversos para expressarse (bater, fazer barulho, chacoalhar etc.);
Imitar gestos, movimentos, sons, palavras de outras crianças e adultos, animais, objetos e fenômenos da natureza.
- perceber os sons e reagir a sons e músicas, acompanhados de movimentos corporais;
Imitar e criar movimentos próprios, em danças, cenas de teatro, narrativas e músicas.
- acessar obras de arte que criem referências para sua expressão.

Fonte: Elaborado pelas autoras 


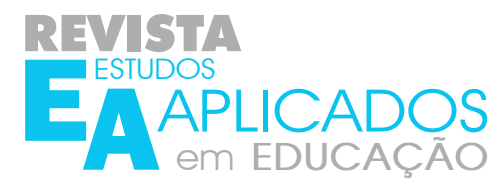

Campo de Experiência: Oralidade e escrita

0 a 1 ano

Objetivos

\begin{tabular}{|c|c|c|c|}
\hline $\begin{array}{l}\text { Reconhecer quando é } \\
\text { chamado por seu nome } \\
\text { e reconhecer os nomes } \\
\text { de pessoas com quem } \\
\text { convive. }\end{array}$ & $\begin{array}{l}\text { - cantar acrescentando o } \\
\text { nome do bebê a música e } \\
\text { dos demais colegas. }\end{array}$ & $\begin{array}{l}\text { Dialogar com crianças e } \\
\text { adultos, expressando seus } \\
\text { desejos, necessidades, } \\
\text { sentimentos e opinióes. }\end{array}$ & $\begin{array}{l}\text { - conversar com as } \\
\text { crianças e estimular } \\
\text { o diálogo entre as } \\
\text { crianças, destas com os } \\
\text { adultos, incluindo } \\
\text { funcionários(as) e } \\
\text { gestores(as); } \\
\text { - responder às crianças, } \\
\text { criando uma relação de } \\
\text { segurança e cooperação; }\end{array}$ \\
\hline $\begin{array}{l}\text { Demonstrar interesse ao } \\
\text { ouvir a leitura de poemas } \\
\text { e a apresentação de } \\
\text { músicas. }\end{array}$ & $\begin{array}{l}\text { - ler, contar, recontar, } \\
\text { inventar, } \\
\text { dramatizar histórias para } \\
\text { os bebês. }\end{array}$ & $\begin{array}{l}\text { Identificar e criar diferentes } \\
\text { sons e reconhecer rimas e } \\
\text { aliteraçóes em cantigas de } \\
\text { roda e textos poéticos. }\end{array}$ & $\begin{array}{l}\text { - cantar e apresentar } \\
\text { imagens que } \\
\text { representem as palavras } \\
\text { da musica, salientando } \\
\text { aquelas que rimam. } \\
\text { - ouvir diferentes sons } \\
\text { (músicas de } \\
\text { ritmos variados cantadas } \\
\text { ou instrumentais, } \\
\text { cantigas de roda etc.); }\end{array}$ \\
\hline $\begin{array}{l}\text { Reconhecer elementos das } \\
\text { ilustraçôes de histórias, } \\
\text { apontando-os, a pedido } \\
\text { do adulto-leitor. }\end{array}$ & $\begin{array}{c}\text { - interagir com a criança } \\
\text { durante as historias, } \\
\text { utilizar figuras para contar } \\
\text { histórias e cantar com } \\
\text { eles. }\end{array}$ & $\begin{array}{l}\text { Formular e responder } \\
\text { perguntas sobre fatos } \\
\text { da história narrada, } \\
\text { identificando cenários, } \\
\text { personagens e principais } \\
\text { acontecimentos. }\end{array}$ & $\begin{array}{l}\text { - questionar a criança } \\
\text { durante a historia sobre } \\
\text { os personagens, sobre o } \\
\text { que está acontecendo, } \\
\text { responder perguntas } \\
\text { feitas por elas. }\end{array}$ \\
\hline $\begin{array}{c}\text { Ter contato com } \\
\text { diferentes } \\
\text { gêneros textuais (poemas, } \\
\text { fábulas, contos, receitas, } \\
\text { quadrinhos, anúncios } \\
\text { etc.). }\end{array}$ & $\begin{array}{l}\text { - trazer toda aula um } \\
\text { gênero textual diferente } \\
\text { para que a criança } \\
\text { entenda que existem } \\
\text { várias formas de se } \\
\text { expressar. }\end{array}$ & $\begin{array}{c}\text { Ampliar o contato com } \\
\text { diferentes gêneros textuais } \\
\text { (parlendas, histórias de } \\
\text { aventura, tirinhas, cartazes } \\
\text { de sala, cardápios, notícias } \\
\text { etc.). }\end{array}$ & $\begin{array}{l}\text { - pedir que as crianças } \\
\text { tragam uma receita } \\
\text { e fazer o que e } \\
\text { proposto nela. Ler um } \\
\text { cardápio e mostrar sua } \\
\text { funcionalidade. Explorar } \\
\text { os diferentes gêneros } \\
\text { textuais e suas funçóes. }\end{array}$ \\
\hline
\end{tabular}

Fonte: Elaborado pelas autoras
1 a 3 anos
Atividades

Objetivos

Atividades
- conversar com as

crianças, destas com os

gestores(as);

criando uma relação de

imagens que

aquelas que rimam.

- ouvir diferentes sons

(músicas de

ritmos variados cantadas

ou instrumentais,

- questionar a criança

de a historia sobre

personagens, sobre o

feitas por elas.

Pedir que as crianças

gam uma receita

proposto nela. Ler um

cuncionalidade. Explorar

os diferentes gêneros

textuais e suas funçóes. 


\section{Objetivos}

Explorar e descobrir as propriedades de objetos e materiais (odor, cor, sabor, temperatura).

\section{Atividades}

- Brincar com água, terra, areia, fazendo pasta, conhecendo texturas;

- ter experiências com alimentos, sabores, cheiros e texturas

\section{Objetivos}

Explorar e descrever semelhanças e diferenças entre as características e propriedades dos objetos (sonoridade, textura, peso, tamanho, posição no espaço).

\section{Atividades}

- explorar diferentes objetos

(de plástico, madeira, isopor, emborrachados, vidro, tecido etc.).

- Utilizar outros espaços

- praças, parques, equipamentos públicos

- possibilitar brincadeiras com terra, areia, água, argila, meleca de

farinha etc., criando situaçōes de diálogo;
Observar, relatar e descrever incidentes do cotidiano e fenômenos naturais (luz solar, vento, chuva etc.).
- para favorecer as vivências em áreas externas;

- garantir às crianças vivências que envolvam a observaçáo, o amor, o respeito, a solidariedade e a preservaçáo da natureza;

\section{Manipular, experimentar, arrumar e explorar o espaço por meio de experiências de} deslocamentos de si e dos objetos.
- engatinhar, movimentarse e empurrar objetos (bolas, objetos de espuma, cubos de borracha, entre outros);

\section{- Segurar a própria} mamadeira - pegar e segurar a chupeta e objetos queridos;

\section{Identificar relaçôes} espaciais (dentro e fora, em cima, embaixo, acima, abaixo, entre e do lado) e temporais (antes, durante e depois).

\section{Analisar situações} problema do cotidiano, levantando hipóteses, dados e possibilidades de solução.

\section{deslocar-se em}

diferentes sentidos; sentar, pular, arrastar, engatinhar, empoleirar.

- repartir, dividir,

(re)contar objetos, alimentos, etc.; - separar e classificar objetos por diferentes atributos (por cores, tamanhos, formas etc.); 


\section{Considerações finais}

A Psicologia do Desenvolvimento é uma disciplina básica dentro da Pedagogia, pois permite conhecer e trabalhar tanto com as crianças como com os adolescentes e adultos. Auxilia o educador, mostrando quais habilidades, capacidades e limitaçóes de cada faixa etária nos vários aspectos da personalidade (motores, emocionais, intelectuais, etc.) ajudando-o a estabelecer programas escolares e metodologias de ensino adequadas, bem como programas esportivos e recreativos.

A teoria de Vigotsky trouxe para a Psicologia e para a educação de forma geral, uma nova forma de observar o desenvolvimento humano. Suas teses valorizam o papel da escola e do professor, pois oferecem elementos imprescindíveis para a compreensão da integração entre ensino, aprendizagem e desenvolvimento. Tornando claro que as conquistas individuais resultam de um processo compartilhado e o individual depende do social.

Os três primeiros anos da infância são essenciais para todo o desenvolvimento futuro da criança. É nesse período que ela faz três grandes conquistas: o andar ereto, o aprendizado da língua materna e as primeiras manifestaçôes do intelecto, ao desenvolver o pensar. Os estudos dos autores Karl König e Valeria Mukhina se complementam e apresentam vários aspectos importantes para que a criança alcance cada uma das três conquistas características da primeira infância.

Por intermédio de tudo isso e das contribuições da Base Nacional Comum curricular foi possível encontrar diversas atividades próprias para cada etapa do desenvolvimento da criança, de acordo com cada campo de experiência e com os eixos estruturantes da educação infantil.

Entende-se que náo é o volume de atividades ou conhecimentos que importa, mas sim a qualidade deles e o quanto a criança tem assimilado aquilo que tem sido proposto. $O$ professor deve respeitar as singularidades de cada aluno e entender as diferentes relaçôes que ele estabelece com o conhecimento. Uma reflexão constante sobre a prática, a formação continuada, a intencionalidade ao educar são fatores essenciais para o sucesso do processo de ensino-aprendizagem.

\section{Referências}

BASTOS, Alice Beatriz Barretto Izique. Wallon e Vigotsky: Psicologia e educação. São Paulo: Ediçôes Loyola, 2014.

BOYDE, Denise; BEE, Helen. A Criança em Crescimento.1.ed. Porto Alegre: Artmed, 2011.

BRASIL. Ministério da Educação. Base Nacional Comum Curricular. Proposta final. Brasília: MEC, 2016. Disponível em: <http://basenacionalcomum.mec.gov.br/images/BNCC_publicacao.pdf>. Acesso em: 21 ago. 2017.

BRASIL. Ministério da Educação. Diretrizes Curriculares Nacionais para Educaçáo Infantil. Disponível em:<http://www.siteal.iipe.unesco.org/sites/default/files/bra__educacion_infantil.pdf> Acesso em: 21 ago. 2017. 
FOSSILE, Dieysa K. Construtivismo versus sociointeracionismo: uma introduçáo às teorias cognitivas. Revista Alpha, Patos de Minas, UNIPAM. 2010. Disponível em: $<$ http://alpha.unipam.edu.br/documents/18125/23730/construtivismo versus socio interacionsimo.pdf.> Acesso em:13 de Out. de 2016.

GIL, Antonio Carlos. Métodos e técnicas de pesquisa social. 6.ed - 6.reimpr. - São Paulo: Atlas, 2014.

KÖNIG, Karl. Os três primeiros anos da criança: A conquista do andar, do falar, e do pensar, e o desenvolvimento dos três sentidos superiores. 5 ed. rev. e atual. São Paulo: Antroposófica. 2011.

LURIA, Alexander Romanovich. Desenvolvimento Cognitivo: seus fundamentos culturais e sociais. 7.ed. São Paulo: Ícone, 2013.

MUKHINA, Valeria. Psicologia da idade pré-escolar. 1.ed. São Paulo: Martins Fontes, 1995

PALANGANA, Isilda Campaner. Desenvolvimento e aprendizagem em Piaget e Vigotski:a relevância do social. 6.ed. São Paulo: Summus, 2015.

REGO, Tereza Cristina. Vigotsky: uma perspectiva histórico-cultural da educação. 25. ed. Rio de Janeiro: Vozes, 2014.

RIPPER, Afira V. Significaçáo e mediaçáo por signo e instrumento. Temas psicol., Ribeirão Preto, v. 1, n. 1, p. 25-30, abr. 1993. Disponível em <http://pepsic.bvsalud. org/scielo.php?script=sci_arttext\&pid=S1413-389X1993000100005\&lng=pt\&nrm=iso>. Acesso em: 23 out. 2016.

STADLER, Gesane; ROMANOWSKI, Joana P.; LAZARIN, Luciane; ENS, Romilda T.; VASCONCELLOS, Sílvia. Proposta pedagógica interacionista. Disponível em: <http://www.pucpr.br/eventos/educere/educere2004/anaisEvento/Documentos/CI/TC-CI0087.pdf> Acesso em: 01 de Outubro de 2016.

VYGOTSKI, Lev Semenovich. A formaçáo social da mente: o desenvolvimento dos processo psicológicos superiores. 7.ed. São Paulo: Martins Fontes, 2007. 